\title{
Endoscopy-Assisted Laparoscopic Cystogastrostomy
}

Surgery, percutaneous drainage and therapeutic endoscopy offer a variety of treatment options for the management of pancreatic pseudocyst $(1-3)$. The decision demands an understanding of the natural history of the disease and an appreciation of the strengths and weaknesses of these procedures. We report here on a complete resolution of a large, recurrent pseudocyst by endoscopy-assisted laparoscopic cystogastrostomy as a modality of endo-organ procedures.

H. J., a 36-year-old man, was referred to our hospital because of abdominal pain and a clinically demonstrated abdominal mass. Acute pancreatitis and repeated percutaneous drainage of a pancreatic pseudocyst were in his past medical history. Abdominal ultrasound and CT showed a large pseudocyst $-180 \mathrm{~mm}$ in diameter involving the body of the pancreas.
A laparoscopic approach was selected for cystogastrostomy. After endoscopic insufflation and transillumination of the stomach, two $10 \mathrm{~mm}$ inner-balloon operative ports (4) were introduced into the stomach. After endoscopically (GIF 100 Olympus) confirming that the balloon portion was in the gastric lumen, the side viewing endoscope (TJF 2 video endoscope, Olympus) was inserted to replace the other one. The cystogastrostomy, $4 \mathrm{~cm}$ wide, was created by cauterization at the corpus-antrum junction in the posterior wall, in the area of the most marked bulging (Figure 1). The necrotic pancreatic debris, too, was removed with the grasping forceps from the bottom of the cyst (Figure 2). After removal of the ports from the stomach, direct suturing through the abdominal wall port entry site was accomplished. The postoperative course was uneventful. Control CT 6 months later showed no sign of recurrence.

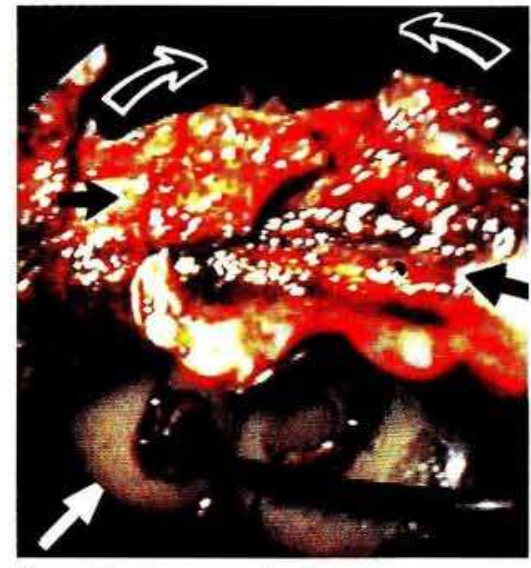

Figure 1: The completed cystogastrostomy The lower arrow indicates the two operative ports in the stomach, the black ones show the thickness of the orifice, and the upper arrows point into the inside of the cyst. 


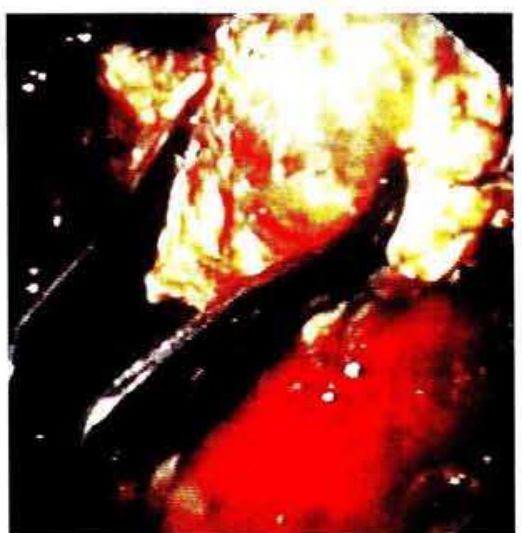

Figure 2: Forceps grasping the tissue debris at the bottom of the cyst.

The advantages of this endoscopy-assisted laparoscopic procedure are as follows. A side-viewing endoscope offers a wide view of the operation area; with its aid both ports can be used for manipulation, the cystogastrostomy can be made as large or small as necessary, clogging can be avoided, suture ligation of bleeding sites is possible and the debris at the bottom of the cyst can be removed. This method might be a successful treatment option in carefully selected patients.

A. Altorjay, I. Szántó, J. Garcia, K. Nagy, J. Kiss

Dept. of Surgery, Imre Haynal University of Health Sciences, Budapest, Hungary

\section{References}

1. Binmoeller KF, Seifert H, Walter A, Soehendra N. Transpapillary and transmural drainage of pancreatic pseudocysts. Gastrointest Endosc 1995; 42: 219-24.

2. Smits ME, Rauws EA, Tytgat GN, Huibregtse K. The efficacy of endoscopic treatment of pancreatic pseudocysts. Gastrointest Endosc 1995; 42: 202-7.

3. Dohmoto M, Rupp KD; Hunerbein M, Schlag PM. Endoskopische Drainage von Pankreaspseudozysten. Dtsch Med Wochenschr 1995; 120: 1647-51

4. Filipi CJ, Wetscher GJ, DeMeester TR, et al. Development of endo-organ surgery and potential clinical applications. In: Peters JH, DeMeester TR, Minimally invasive surgery of the foregut. St. Louis, MO: Quality medical Publishing, 1994; 288-308.

Corresponding Author

A. Altorjay, M.D., Ph.D.

Károly krt. 23

1075 Budapest, Hungary

Fax: + 36-1-2702382 